\title{
On some Features of the Use of High-Speed Conical Valve for the Incident Shock Wave Formation in Shock Tubes
}

\author{
Mikhail Kotov \\ Ishlinsky Institute for Problems in Mechanics RAS, \\ Moscow, 119526, Russia \\ kotov@ipmnet.ru
}

\begin{abstract}
This article describes some features of the use of a high-speed electric pneumatic valve in the hypersonic aerodynamic shock tube (HAST) capable of generating well-formed incident shock waves. The use of this device is due to the requirements for the implementation of automation processes and good repeatability of the initial gas-dynamic parameters of experiments, for which conventional methods of diaphragm rupture are not suitable. The valve performs reliable operation in a wide pressure range at the driver section of shock tube; there is no need to adjust it and for setting it from run to run. Shock waves with a Mach number of up to 3 were generated in air at a pressure of 1 mbar. One of the features of the valve is to provide a good level of flow around the device separating the sections of the shock tube, which helps to optimize the efficiency of the installation and automate the experiment procedure. The results of the comparison of the data obtained in experiments conducted using diaphragm and the valve are given. It is shown that the device is capable of generating a well-formed incident shock wave in the shock tube.
\end{abstract}

Keywords: shock tube, diaphragm, high-speed valve, incident shock wave.
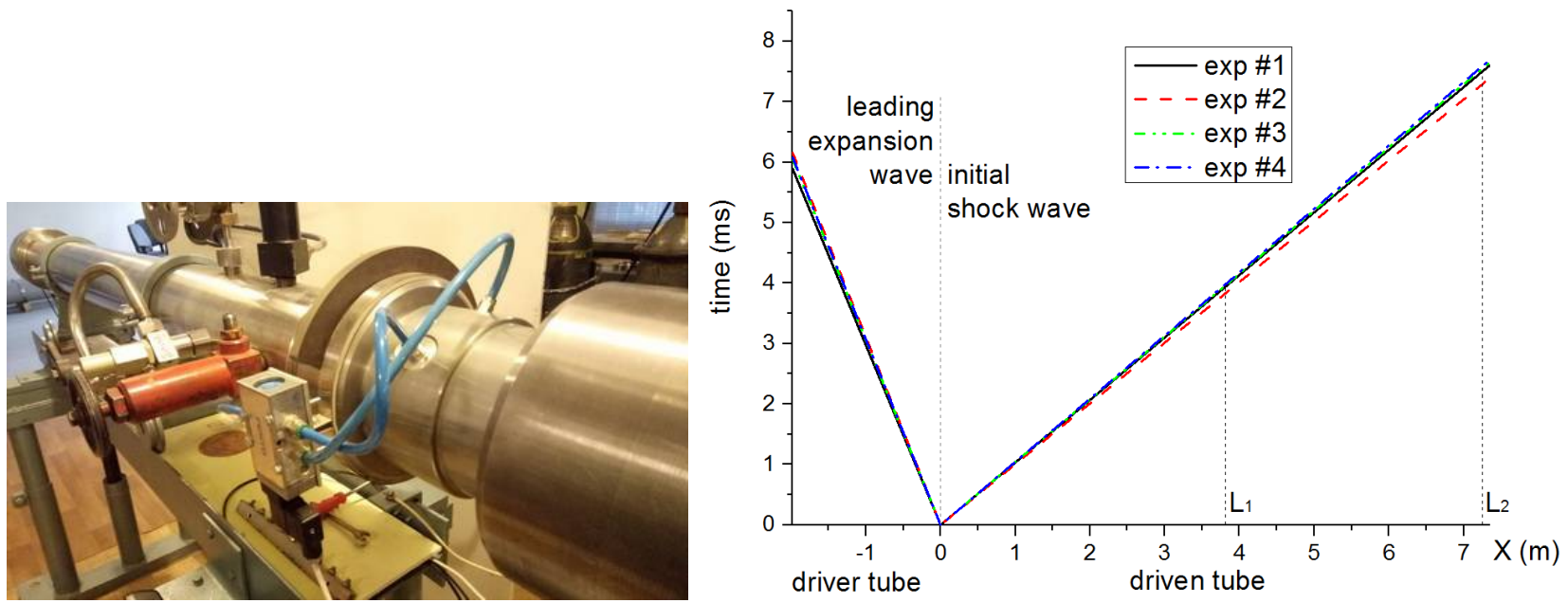

High-speed valve installed on the HAST. Shooting direction: towards the driver tube (from the left). $\mathrm{X}$-t diagram of the incident shock wave and the leading expansion wave, obtained in experiments 1-4 (from the right). 


\title{
О некоторых особенностях использования быстродействующего конического клапана для формирования падающей ударной волны в ударных трубах
}

\author{
М.А. Котов \\ Федеральное государственное бюджетное учреждение науки \\ Институт проблем механики им. А.Ю. Иилинского Российской академии наук, \\ Россия, Москва, 119526, пр-т Вернадского, 101, к.1 \\ kotov@,ipmnet.ru
}

\begin{abstract}
Аннотация
В данной статье описываются некоторые особенности использования быстродействующего пневматического клапана с электромагнитным запуском в ударной трубе, способного генерировать хорошо сформированные падающие ударные волны в камере низкого давления со значением отношения длины к диаметру в 92. Использование данного устройства обусловлено требованиями, предъявляемыми к реализации процессов автоматизации и хорошей повторяемости начальных газодинамических параметров, для обеспечения которых обычные методы разрыва диафрагмы не подходят. Клапан надежно функционирует в широком диапазоне давлений на входном сечении, необходимость его регулировки и настройки отсутствует. Ударные волны с числом Маха до $\mathrm{M}=3$ генерировались в воздухе при давлении 1 мбар. Одна из особенностей клапана заключается в обеспечении хорошего уровня обтекаемости устройства, разделяющего секции ударной трубы, что помогает оптимизировать эффективность работы установки и автоматизировать проведение экспериментов.
\end{abstract}

Ключевые слова: ударные трубы, диафрагма, быстродействующий клапан, падающая ударная волна.

\section{1. Введение}

Установки типа ударных труб являются достаточно эффективным инструментом для создания и изучения высокоэнтальпийных течений газа [1-4]. Они широко используются при проведении исследований в различных областях физической газодинамики и химической кинетики [5-10]. Принцип функционирования ударных труб основан на внезапном разрыве диафрагмы, отделяющей камеру высокого давления (содержащую толкающий газ) от камеры низкого давления (содержащую исследуемый газ), чтобы создать ударную волну $[1,2]$. Несмотря на то, что диафрагма, предназначенная для раскрытия, обеспечивает достаточно простой способ почти мгновенного устранения т.н. «перегородки» между секциями установки, этот метод имеет ряд практических недостатков. Для каждого эксперимента должна использоваться новая диафрагма, что делает метод трудоемким и неудобным для автоматизации. Также это может служить причиной плохой повторяемости результатов экспериментов из-за непоследовательного разрыва каждой отдельной диафрагмы, хотя возможно получать давление раскрытия в пределах воспроизводимости с отклонением в несколько процентов при помощи использования диафрагмы с перекрестным насечением $[11,12]$. Кроме того, фрагменты 
диафрагмы могут отрываться, ударять и повреждать как внутренние стенки секций установки, так и дорогостоящие средства измерения, расположенные внутри. После данных случаев требуется частичный или полный разбор ударной трубы для прочистки, удаления фрагментов диафрагмы [13] и приведения элементов конструкции установки и средств измерения в рабочее состояние.

Для преодоления этих проблем были разработаны конфигурации бездиафрагменных ударных труб, в которых вместо диафрагмы использовались различные типы быстродействующих устройств раскрытия. Такие контуры установок особенно предпочтительны, когда требуются высокая повторяемость начальных и рабочих условий экспериментов, их автоматизация. Но при проектировании такого рода устройств необходимо принимать во внимание тот факт, что расстояние, на котором образуется фронт падающей ударной волны, увеличивается прямопропорционально продолжительности времени открытия диафрагмы $[1,2,14]$. Следовательно, основная проблема с бездиафрагменным подходом к проектированию ударных труб заключается в достижении достаточно быстрого времени открытия клапана для того, чтобы генерировать хорошо сформированную ударную волну при разумной длине секции низкого давления.

В данной статье описывается некоторые особенности бездиафрагменного функционирования гиперзвуковой ударной аэродинамической трубы (ГУАТ) ИПМех РАН, в которой клапан с быстродействующим пневматическим электроприводом КБ-80-50 [15-20] заменяет функцию разрывной диафрагмы. Основные причины, побудившие заменить диафрагменный блок на конфигурацию бездиафрагменного функционирования, состояли в том, чтобы облегчить автоматизацию работы установки и обеспечить гарантированную повторяемость результатов.

\section{2. Устройство быстродействующего клапана}

Система конструктивных элементов клапана имеет осесимметричное ориентирование, крепление к секциям установки спереди и сзади устройства предполагается через фланцевые соединения (рис. 1). Для создания противодавления, служащего для быстрого открытия затворного механизма, в состав клапана включен распределитель с электроуправлением, который закрепляется с внешней стороны на корпусе основного блока (рис. 1).

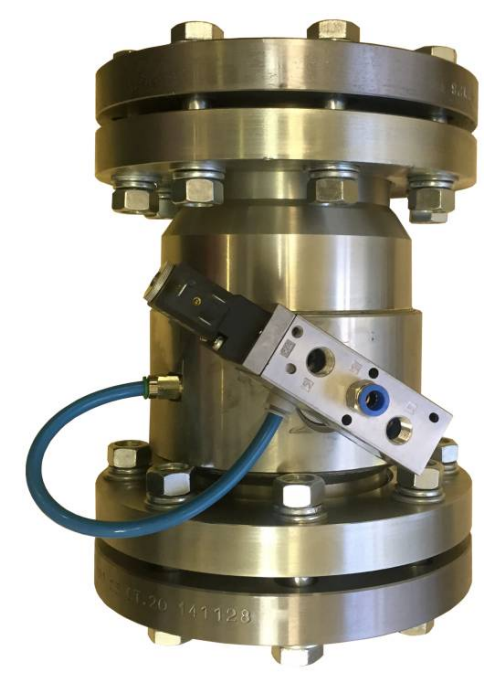

Рис. 1. Общий вид быстродействующего клапана

Устройство может работать с секциями установки, которые содержат сжатый воздух или инертные газы. Внутренний диаметр проходного сечения составляет 80 мм. Время раскрытия основного клапана не превышает 0.002 с $[15,16]$, что сопоставимо с характерными 
временами раскрытия диафрагменных узлов. Проходное сечение клапана закрывается подпружиненным коническим колпаком, внутри которого находится небольшое количество воздуха. При срабатывании управляющего электроклапана воздух из колпака выходит, давление колпака на пружины возрастает и колпак отпирает отверстие проходного сечения. Диапазон рабочих давлений на входе в устройство $0.1 \div 5.0$ МПа, управляющий электроклапан противодавления работает со значениями $0.6 \div 0.8$ МПа.

Запорный колпак (рис. 2) в закрытом клапане опирается на седло и находится в состоянии постоянного побуждения к деформации. При использовании устройства в ударных трубах это играет большую роль, поскольку от данного явления зависят пределы нагнетания рабочих давлении в секциях установки. В работе [17] при помощи проведения численного конечно-элементного расчета была рассмотрена проблема определения разрушающего давления (рис.3), действующего на запорный колпак из материала хостаформ марки C9021GV1/40. Внешний вид такого разрушенного колпака представлен на рис. 4. Разрушение произошло при давлении в 61 атм.

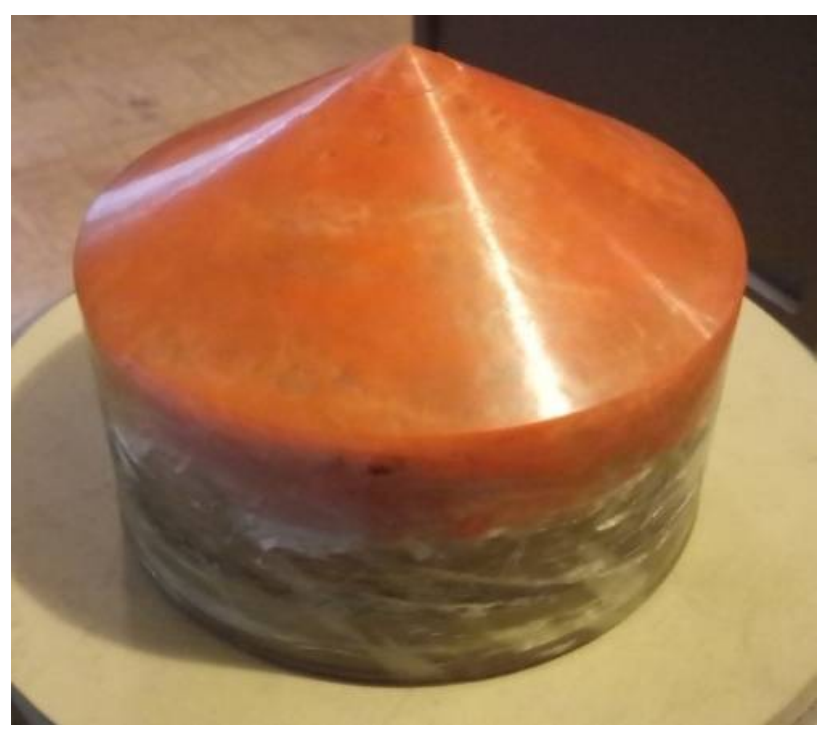

Рис. 2. Фотография запорного колпака клапана $[15,16]$

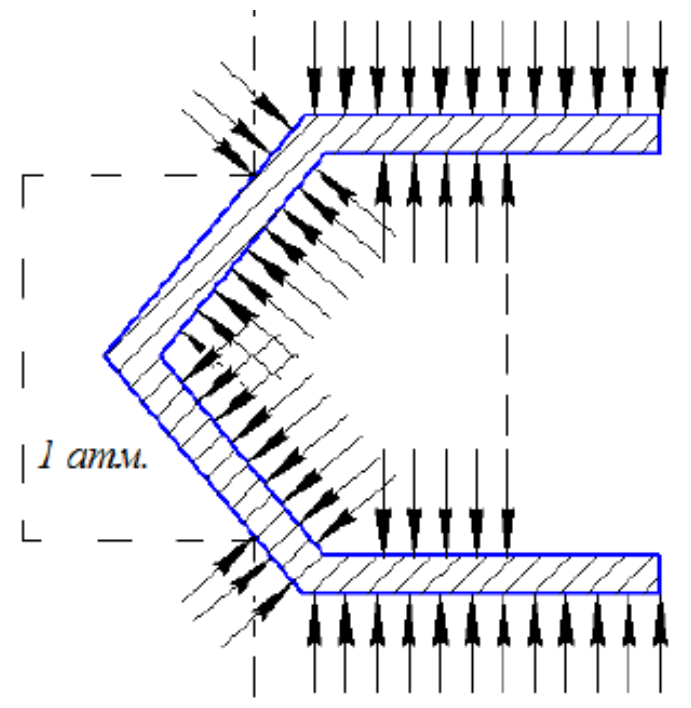

Рис. 3. Нагрузки, прикладываемые к запорному колпаку в работе [17] 


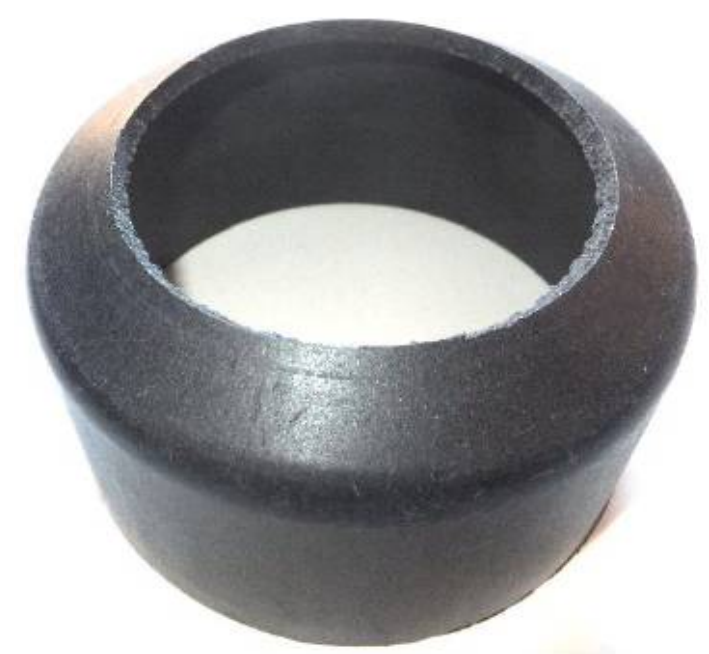

Рис. 4. Разрушенный колпак в работе [17]

\section{3. Негативные последствия использования диафрагмы}

Основная проблема использования диафрагмы в ударных трубах заключается в обеспечении однородности ее раскрытия для выполнения условий повторяемости результатов исследований. В типичном устройстве ударных труб разрыв осуществляется в результате повышения давления толкающего газа в камере высокого давления (КВД), а толщина диафрагмы и глубина насечки подбираются такими, чтобы разрыв произошел при определенной желаемой величине давления $[1,2]$. В результате разрыва диафрагмы несколько лепестков под высоким давлением быстро раскрываются, прижимаясь к внутренним стенкам камеры низкого давления (КНД), где содержится рабочий/исследуемый газ. Разница давлений толкающего и рабочего/исследуемого газов перед началом эксперимента составляет несколько порядков. Для разрыва также может использоваться система ножей, помещенная в диафрагменный блок лезвиями навстречу направлению раскрытия диафрагмы.

При проведении экспериментов в ударных трубах с использованием диафрагмы возникает ряд вопросов, касающихся однородности их поведения при разрыве. В первую очередь, необходимо обеспечивать хорошую повторяемость условий раскрытия (рис. 5).
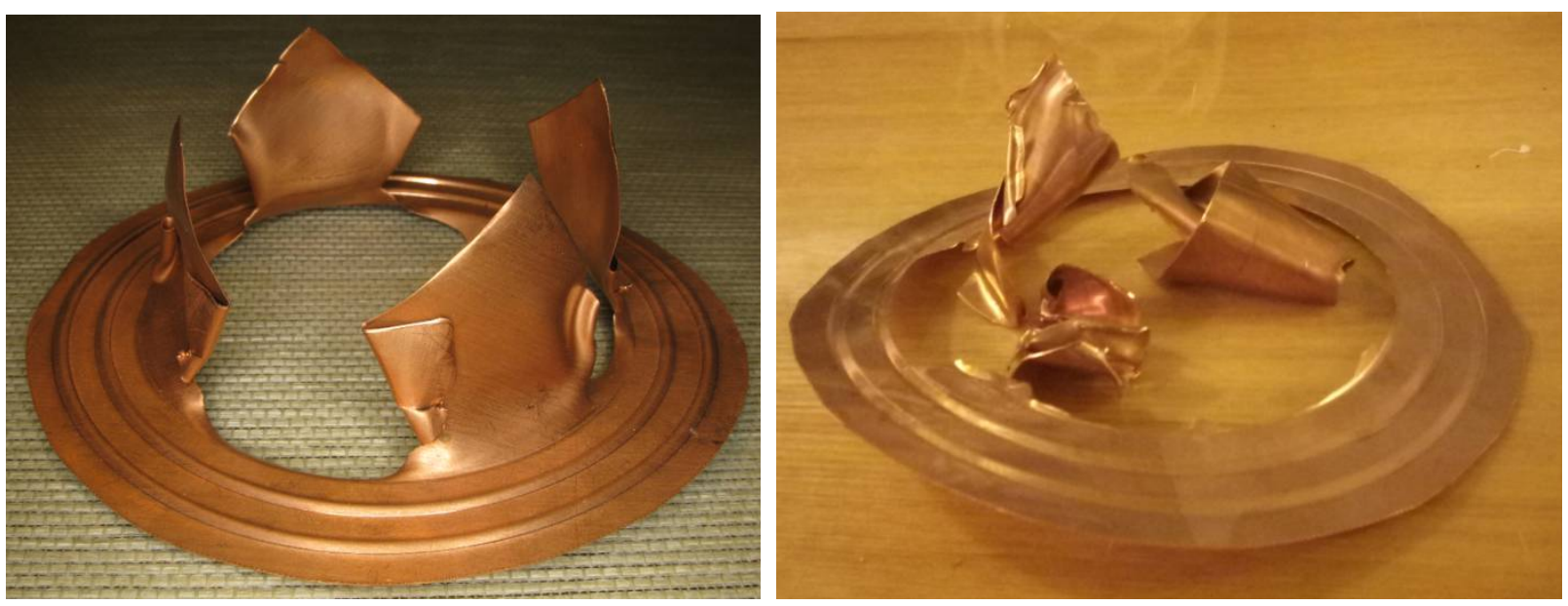

Рис. 5. Равномерно (слева) и неравномерно (справа) раскрытые медные диафрагмы

В случае с насечением диафрагмы требуется проводить данный процесс идентично как по методу, так и по параметрам. Например, если насечение осуществляется под прессом с помощью давления системы заточенных лезвий на образец (диафрагму), нужно обеспечивать контроль значения силы, прикладываемой к лезвиям. Если значение будет меняться, глубина 
насечения будет различаться и насеченные диафрагмы будут раскрываться раньше или позже желаемой величины давления толкающего газа. Если же для раскрытия используются ножи, то для регулировки момента раскрытия необходимо выставлять их на различном от установленной в диафрагменном блоке диафрагмы отдалении (обычно, это величины порядка нескольких мм) и сохранять эти значения от эксперимента к эксперименту. Значения всех подобных параметров получаются опытным путем после проведения серий запусков ударных труб.

Процессы, влияющие на неоднородность раскрытия, зависят от множества факторов: обеспечение герметизации диафрагменного блока, закрепление диафрагмы в месте ее установки, временные характеристики наполнения толкающим газом КВД, эластичность, упругость и прочностные характеристики материала изготовления, равномерность и глубина предварительного насечения диафрагмы, место установки ножей, их острота и форма и т.д. Более подробно данные вопросы, возникавшие на ГУАТ, рассмотрены в [21]. Эти факторы могут оказывать различное влияние на ход эксперимента, в т.ч. крайне негативное. Например, при раскрытии от диафрагмы может оторваться один или несколько лепестков, которые будут находиться в течение всего эксперимента в тракте ударной трубы и оказывать огромное влияние на протекающие ударно-волновые процессы. Более того, лепестки повреждают внутренние стенки секций и чувствительные элементы датчиков и средств измерения, которые расположены в их плоскости (рис. 6).

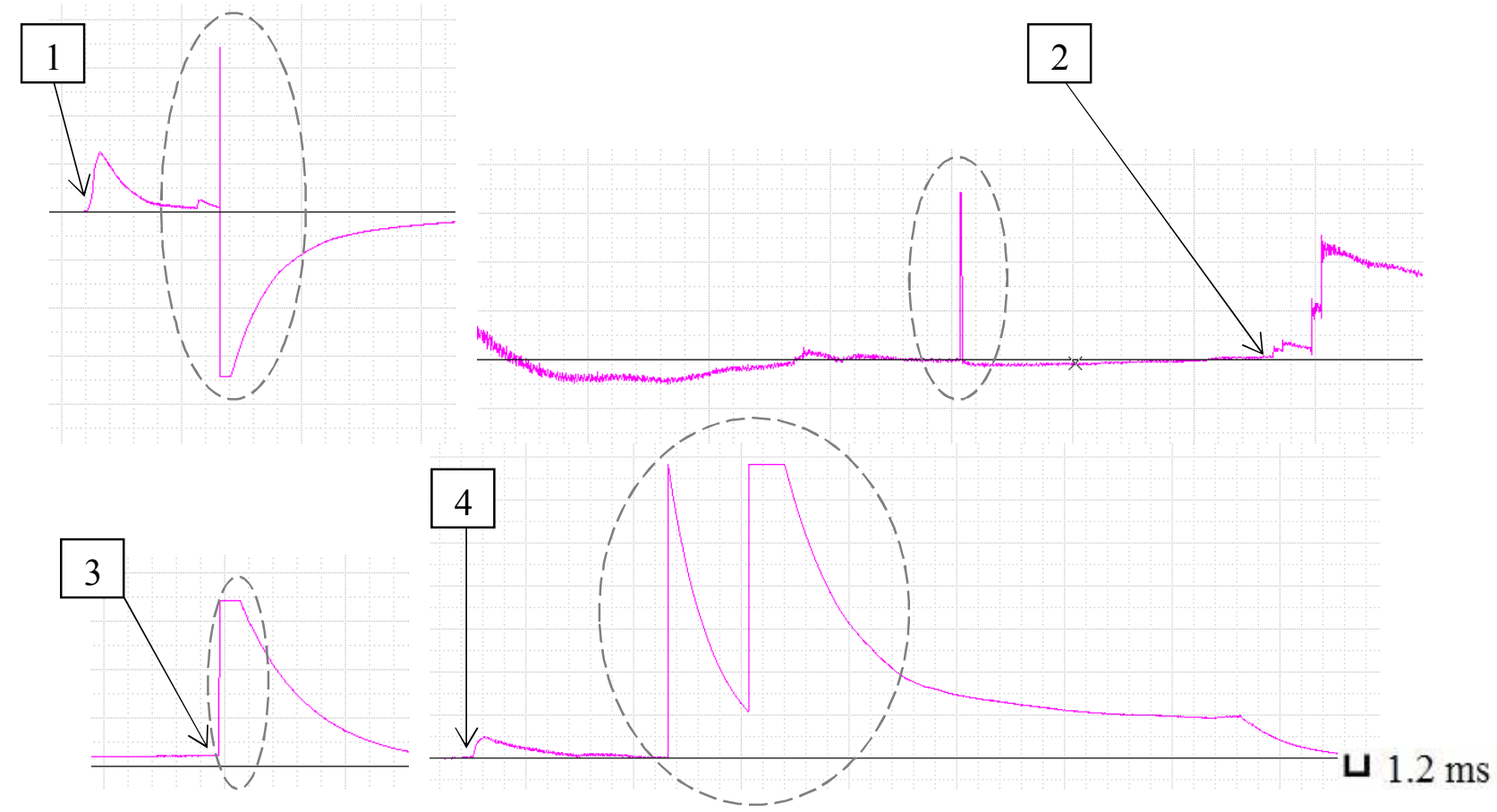

Рис. 6. Показания (в отн.ед.) с датчиков давления, расположенных в конце КНД, свидетельствующие об ударах оторвавшихся лепестков о чувствительные элементы в процессе проведения эксперимента

На рис. 6 показаны осциллограммы различных экспериментов с датчиков давления, расположенных за 100 мм до торцевой стенки КНД. Стрелками обозначены моменты прихода падающих $(1,3,4)$ и переотраженной $(2)$ ударных волн. Стрелки 1 и 4 указывают на проход падающей ударной волны, который после нескольких сотен микросекунд сразу же сменяется приходом отраженной от торца КНД волны сжатия. Далее следует рост и падение давления вследствие прихода контактной поверхности и волны разрежения соответственно. При отрыве лепестков диафрагмы по ходу их увлечения потоком на графиках появляются паразитные всплески давлений (пунктиром на рис. 6 выделены области, свидетельствующие об ударах частей диафрагмы о чувствительные элементы датчиков), что искажает автоматическую 
обработку данных на компьютере. На рис. 7 приведен пример поврежденного оторванным лепестком диафрагмы датчика давления, располагавшегося вблизи торцевой стенки КНД.

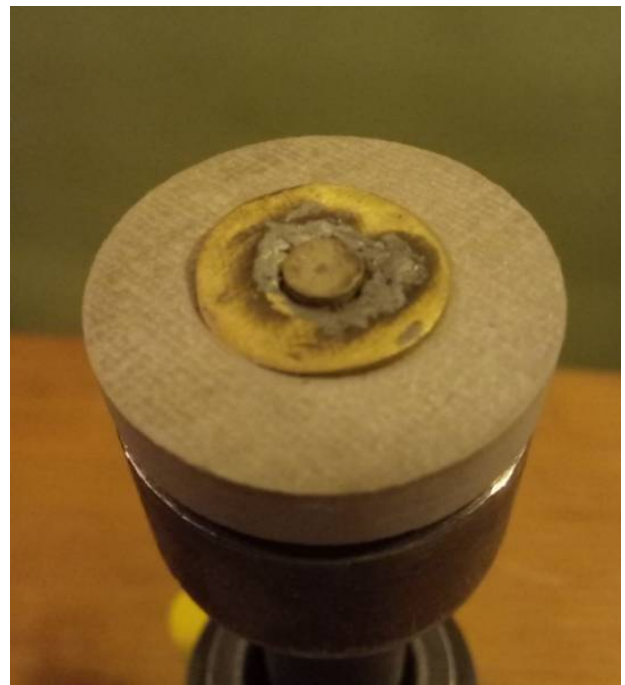

Рис. 7. Датчик давления, поврежденный осколком диафрагмы во время эксперимента

\section{4. Обеспечение функционирования клапана на установке}

Вопросы, возникавшие при монтаже быстродействующего клапана на установке ГУАТ, уже рассматривались в работе [22]. Для расположения устройства между КВД и КНД была осуществлена разработка переходных элементов с фланцевого типа соединения на винтовой. Для создания элементов были разработаны и изготовлены калибры [23, 24]: проходной и непроходной, которые изображены на рис. 8.

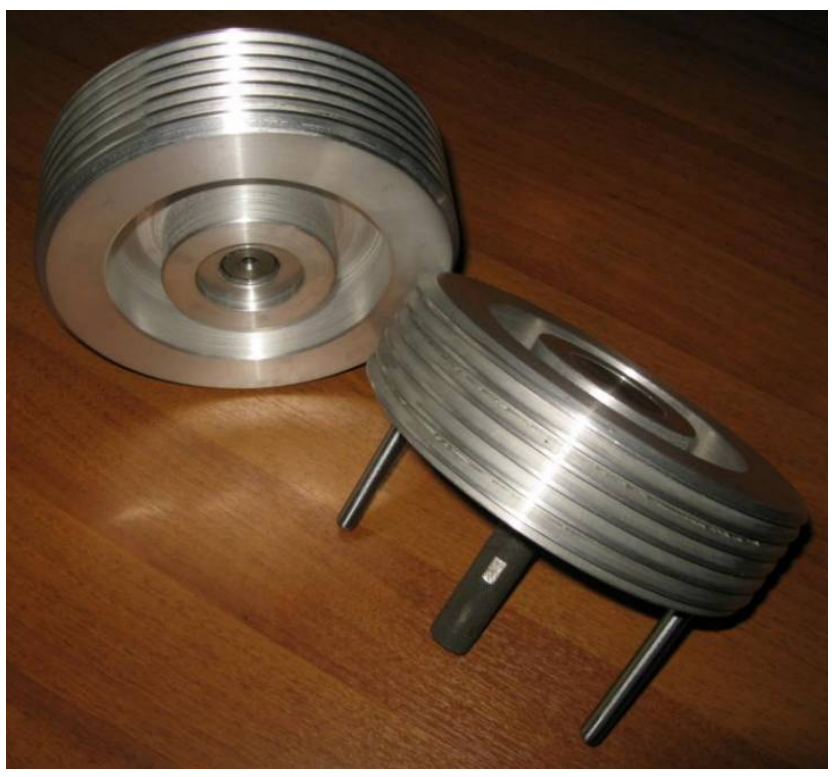

Рис. 8. Спроектированные и изготовленные проходной и непроходной калибры [23-24] для создания переходных элементов крепления клапана на установке

Приведение устройства в действие осуществляется следующим образом. На управляющий клапан (рис. 9) через отдельную газовую систему подается воздух под давлением, приблизительно равным $p_{\text {ynр. }}=0.6$ МПа. На входном сечении устройства путем заполнения толкающим газом камеры высокого давления ГУАТ (рис.10) задается давление в диапазоне 
значений $p_{\text {раб. }}=0.5 \div 5.0$ МПа. На выходном сечении устройства, выходящим в КНД ГУАТ, обеспечивается разрежение рабочего газа до значений $p_{\text {кнд. }}=50 \div 0.1$ кПа. В момент запуска установки на управляющий клапан оператором подается электрический сигнал с характерными параметрами $I=0.2 \mathrm{мA}, U=24 \mathrm{~B}$. Управляющий клапан обеспечивает отвод сжатого воздуха, находившегося под давлением $p_{y n p}$. и подпиравшего запорный колпак, через пусковой клапан (рис. 9). Колпак отпирает отверстие проходного сечения, после чего начинается

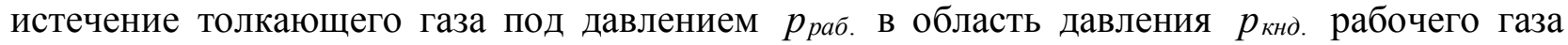
(рис. 10).

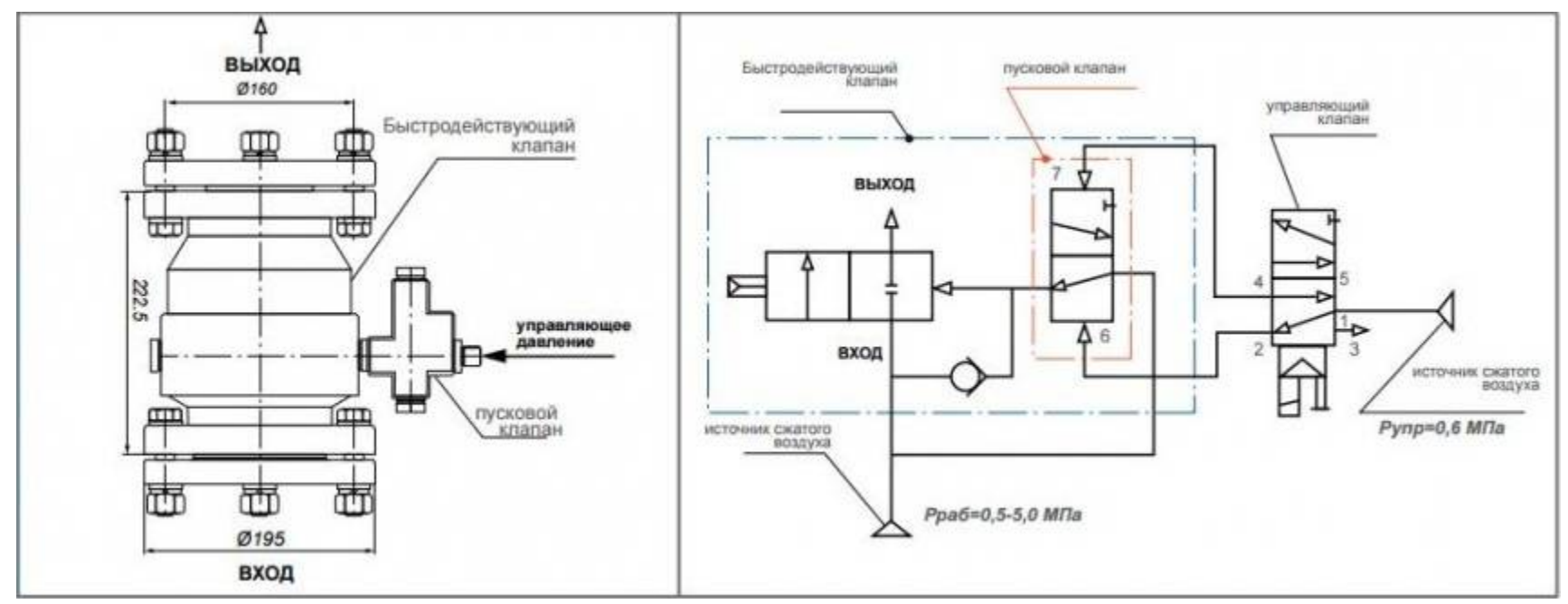

Рис. 9. Габаритный чертеж (слева) и пневмосхема (справа) быстродействующего клапана
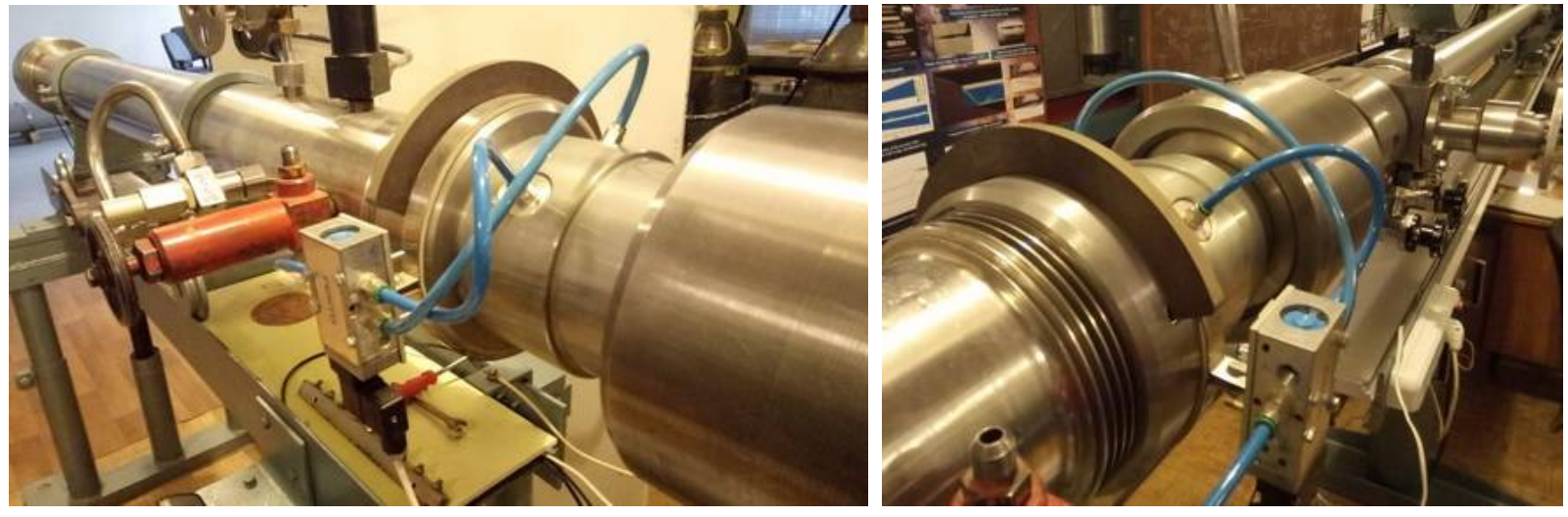

Рис. 10. Быстродействующий клапан, установленный на ГУАТ. Направление съемки: в сторону КВД (слева), в сторону КНД (справа)

\section{5. Сравнение результатов}

\section{1. Формирование фронта падающей ударной волны}

Для анализа результатов регистрации формирования фронтов падающей ударной волны в секциях ударной трубы были проведены эксперименты с использованием диафрагменного блока (рис. 11). Для изготовления диафрагмы использовалась медь марки М1т толщиной 0.3 мм. В качестве толкающего и рабочего газов использовался воздух комнатной температуры $T=300 \mathrm{~K}$, начальные давления в КВД и КВД были равны $p_{\text {квд. }}=p_{\text {раб. }}=3.6 \mathrm{MПа,}$ $p_{\text {кнд. }}=100$ Па. Эксперименты с использованием быстродействующего клапана (см. рис. 10) проводились при тех же начальных параметрах. На рис. 12-15 представлены полученные результаты. 


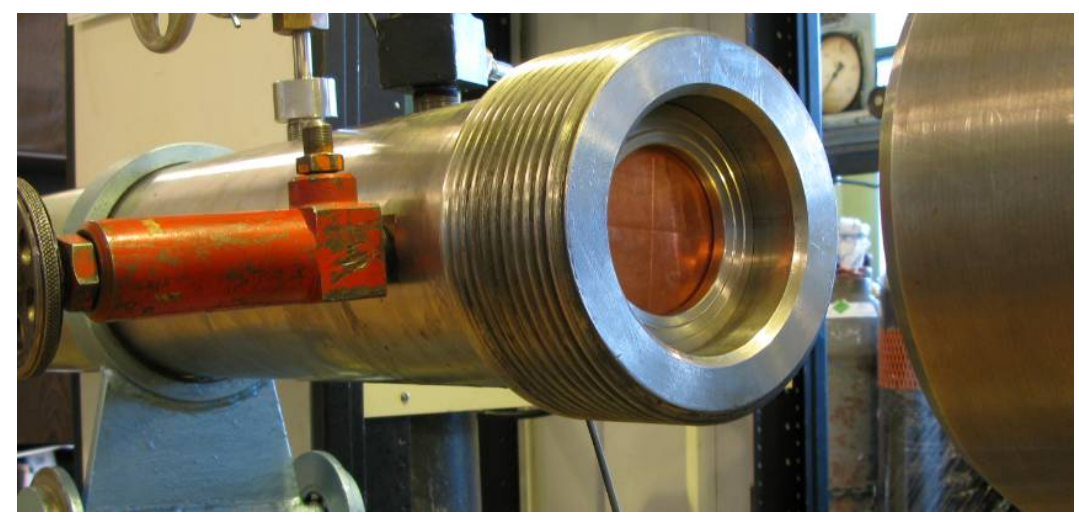

Рис. 11. Диафрагменный блок ГУАТ с установленной насеченной медной диафрагмой

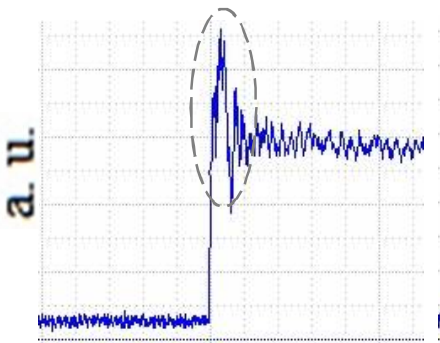

exp.\#1

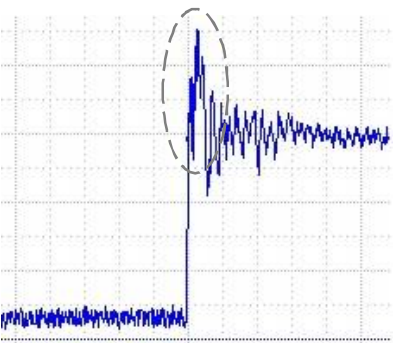

exp.\#2

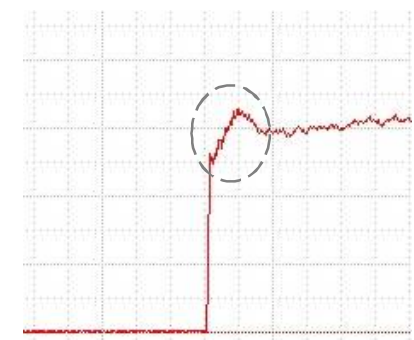

exp.\#3

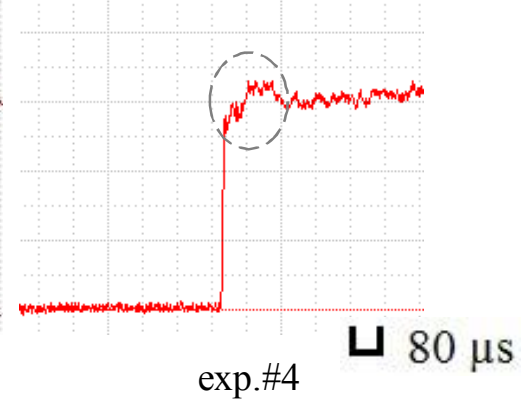

Рис. 12. Показания (в отн.ед.) с датчиков давления, расположенных в середине КНД. Слева (синий сигнал) - эксперименты с использованием диафрагмы (ехр\#1, ехр\#2); справа (красный сигнал) - с использованием клапана (ехр\#3, ехр\#4)

На рис. 12 изображены осциллограммы, полученные с датчиков давления, расположенных в сечении середины секции КНД (внутренний диаметр $d=80$ мм) на расстоянии $L_{1}=3.81$ м от устройств раскрытия. В экспериментах 1 и 2 использовалась диафрагма для раскрытия и датчик рcb 113В24 для измерения с максимально возможным значением давления для регистрации $p_{\max 1}=6.89$ МПа, в экспериментах 3 и 4 использовался клапан и датчик pcb 113В27 с максимальным значением $p_{\max 2}=689$ кПа. Показания ехр\#1, ехр\#2 в областях нулевого сигнала и в периодах, где течение рассматривается как установившееся (за фронтом ударной волны), имеют разные по амплитуде колебаний значения по сравнению с ехр\#3, exp\#4. Это связано с различием в уровнях чувствительности датчиков $\left(p_{\max 1} / p_{\max 2}=10\right)$, обусловленным их градуировочными характеристиками.

Также обращает на себя внимание то, что согласно рис. 12 в случаях с диафрагмой фронт ударной волны имеет немного более резкий характер, чем в экспериментах с клапаном. Некоторая выраженная нестабильность показаний в течение приблизительно 120 мкс после прохода фронта является общей для всех рассматриваемых случаев, хоть и имеет различные модели поведения (рис. 12, выделенные пунктиром области). Вследствие более быстрого раскрытия диафрагмы формируется крутой фронт сигнала падающей ударной волны к моменту прихода к датчику, расположенного на расстоянии $L_{1}$ от диафрагмы. При использовании клапана в этих областях наблюдается более медленный рост давления, что, по-видимому, указывает на продолжение формирования ударной волны. Однако, после прохождения данного периода уровень давления отличается незначительно, что позволяет говорить о хорошей повторяемости результатов. Более подробное сравнение нарастания фронтов сигналов рис. 12 до средних значений, показанных после прохода ударной волны через центр КНД $\left(L_{1}\right)$, представлено на рис. 13. 


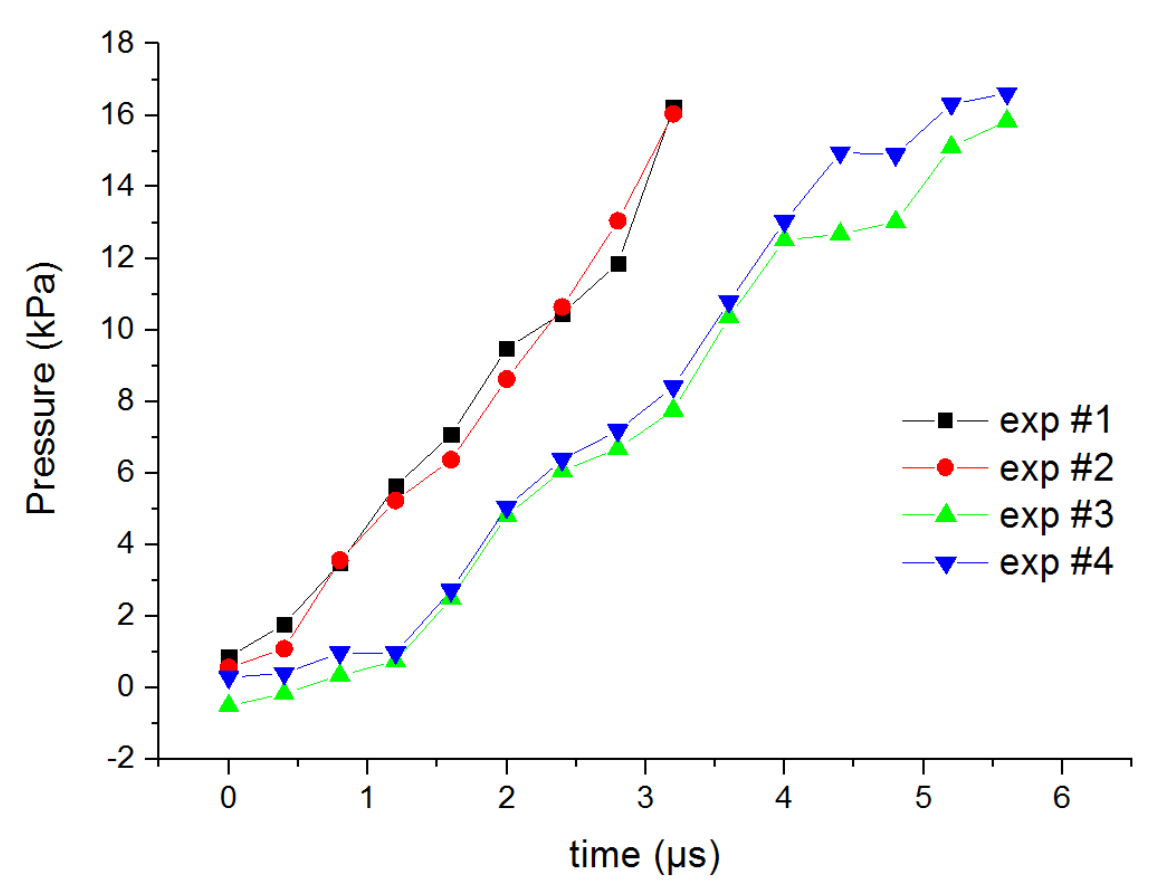

Рис. 13. Сравнение нарастания фронтов падающей ударной волны в середине КНД при использовании диафрагмы и клапана

Регистрация осуществлялась через АЦП с частотой 2.5 МГц. Видно, что время нарастания фронта возмущения в случаях с использованием диафрагмы составляет 3.2 мкс в отличие от использования клапана, где данный рост происходит за 5.6 мкс. Такую разницу можно объяснить различием принципов функционирования устройств. Раскрытие насеченной диафрагмы (рис. 11) под критическим давлением толкающего газа со стороны КВД происходит от центра к краям лепестков, которые прижимаются к стенкам внутреннего сечения секции ударной трубы. Направление раскрытия диафрагмы и направление силы давления, действующей на нее, совпадают. В отличие от диафрагмы клапану для раскрытия необходимо сообщить импульс, направленный противоположно давлению, оказываемому на входное сечение со стороны КВД. Поскольку запорный колпак имеет коническую форму, истечение толкающего газа в КНД в момент раскрытия происходит от края внутреннего сечения к центру, что также оказывает влияние на характер формирования фронта падающей ударной волны. Необходимо отметить, что диаметр чувствительной поверхности датчиков давления равнялся приблизительно 4 мм, и погрешность измерения, связанная с временем прохождения ударной волны по данному элементу (которое составляет порядка 4 мкс) не учитывалась.

На рис. 14 показаны фронты падающих ударных волн, полученных в экспериментах 3 и 4 и проходящих через сечение КНД, расположенное в конце секции, на расстоянии $L_{2}=7.25$ м от быстродействующего клапана. Измерения производились датчиком pcb 113В24. Время нарастания фронтов падающих ударных волн, сгенерированных быстродействующим клапаном, сократилось с 5.6 мкс в середине КНД $\left(L_{1}\right)$ до 4.4.мкс в конце секции ( $\left.L_{2}\right)$. Такая разница связана с увеличением калибра распространения скачка. Как видно из рис. 11 , калибра $L_{1} / d=47.6$ вполне достаточно для формирования четкого фронта падающей ударной волны. При калибре $L_{2} / d=90.6$ скачок имеет более резкий фронт вследствие прохождения большего расстояния по невозмущенному газу. Характерные времена нарастания фронтов в экспериментах 1 и 2 в данном сечении изменяются незначительно и составляют порядка 3 мкс. Получаемые с помощью клапана (рис. 13, 14) временные характеристики вполне соответствуют ударно-волновым процессам, происходящим в ударной трубе при данных начальных параметрах и скоростях распространения возмущений. 


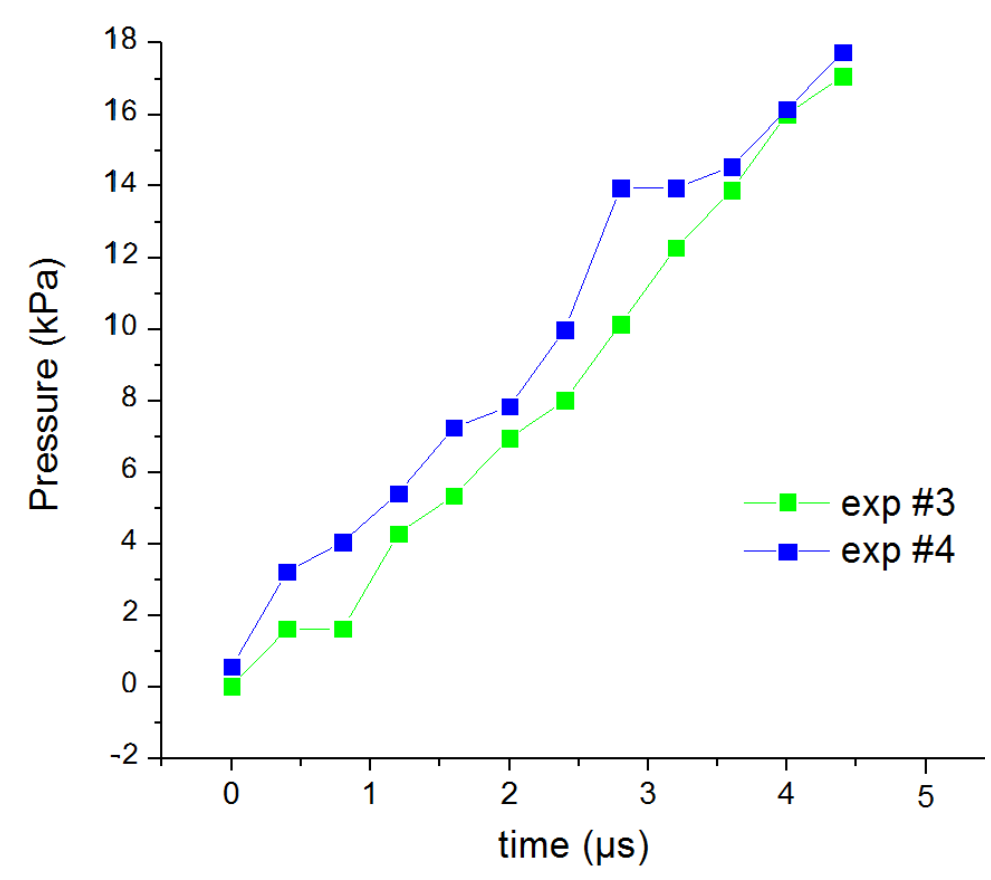

Рис. 14. Сравнение нарастания фронтов падающей ударной волны в конце КНД при использовании диафрагмы и клапана

\section{2. Распространение возмущений}

На рис. 15 представлены пространственно-временные диаграммы экспериментов 1-4. На них показано распространение головной волны разрежения и падающей ударной волны, образовавшихся после раскрытия диафрагмы и клапана. Ход волн представлен до встречи с торцевыми стенками КВД и КНД соответственно, динамика распространения отраженных от торцов возмущений не приводится. Время раскрытия клапана (рис. 15, ехр \#3,4) не учитывается. Делается предположение, что на расстоянии $L_{1}$ фиксируется прохождение ударной волны с уже установившейся скоростью.

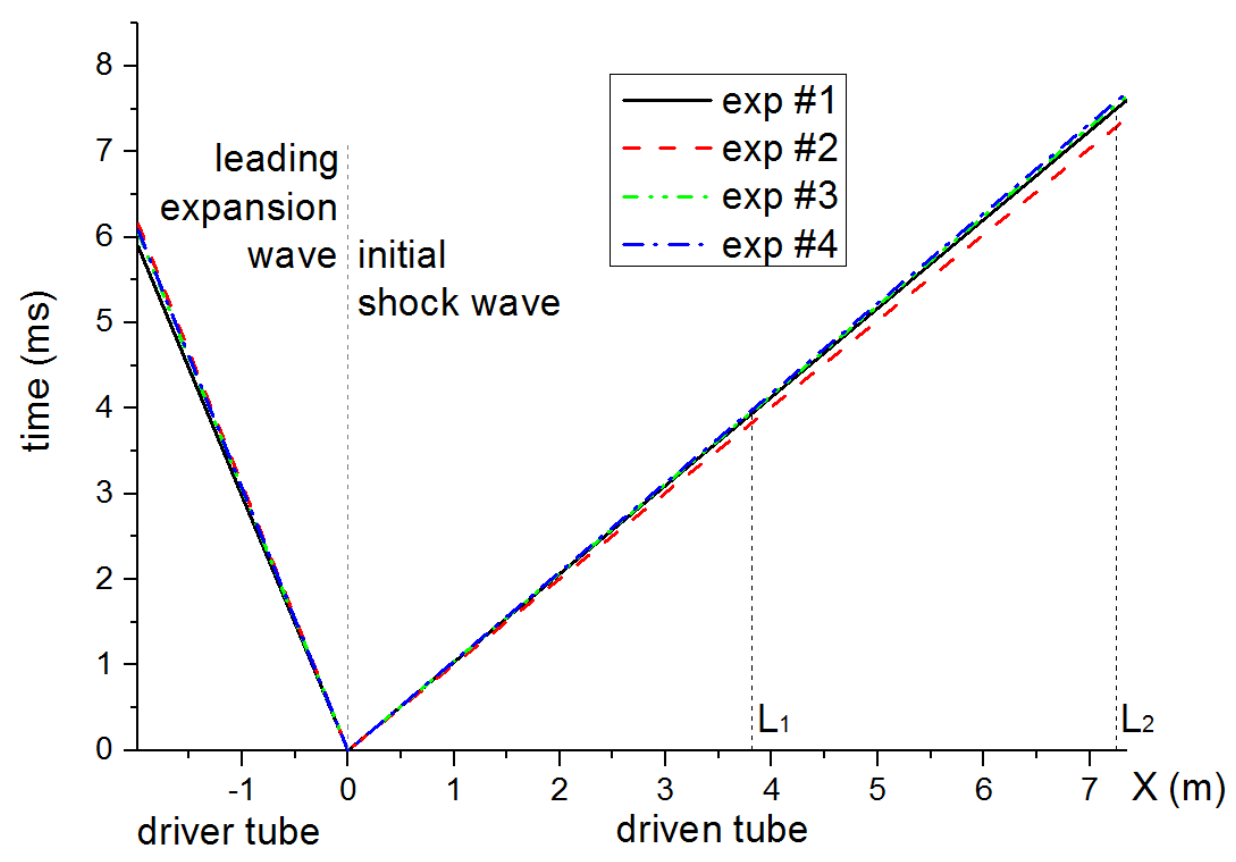

Рис. 15. X-t диаграммы падающей ударной волны и головной волны разрежения, полученных в экспериментах 1-4 
Скорости распространения ударных волн в экспериментах $1-4: \quad V_{y 6.1}=966 \mathrm{~m} / \mathrm{c}$, $V_{y b .2}=994 \mathrm{~m} / \mathrm{c}, V_{y b .3}=960 \mathrm{~m} / \mathrm{c}, V_{y b .4}=955 \mathrm{~m} / \mathrm{c}$. Различие $V_{y в .1}$ и $V_{y b .2}$ можно объяснить неоднородностью раскрытия диафрагмы (более подробно этот процесс рассмотрен в разделе 3 и в $[21,22])$. Различие прихода на торцевые стенки КВД и КНД сгенерированных возмущений мало и составляет несколько сотен мкс, что позволяет говорить о хорошем совпадении характеристик газодинамических процессов и удовлетворительном уровне повторяемости результатов.

\section{6. Заключение}

Рассмотрены проблемы использования диафрагмы на установках типа ударных труб, где требуется обеспечение мгновенного убирания перегородки между секциями. Описан принцип функционирования быстродействующего клапана КБ-80-50 на установке ГУАТ ИПМех РАН. Его конструкция включает в себя запорный колпак конической формы с механизмом быстрого открытия, а геометрические особенности обеспечивают хороший уровень обтекаемости, что позволяет устройству эффективно заменять функцию разрывной диафрагмы и обеспечивать надежную степень автоматизации и повторяемости параметров исследований. Приведены результаты сравнения данных, полученных в экспериментах, проведенных с использованием диафрагмы и клапана. Показано, что устройство способно генерировать хорошо сформированную падающую ударную волну в ударной трубе в рассмотренном диапазоне величин начального давления.

\section{Благодарности и ссылки на гранты}

Автор выражает благодарность Л.Б. Рулевой, С.И. Солодовникову и С.Т. Суржикову за помощь в получении экспериментальных данных и консультации при их обработке. Работа поддержана грантом РФФИ 19-01-00515, средствами государственного бюджета (№AАААА17-117021310372-6) и грантом Президента РФ МК-144.2020.1. Экспериментальные исследования выполнены на УНУ ГУАТ ИПМех РАН.

\section{Литература}

1. У Уарные трубы. Сб. статей под ред. Х.А. Рахматуллина, С.С. Семенова, М.: Изд-во иностр. лит., 1965.

2. Райзер Ю.П. Введение в гидрогазодинамику и теорию ударных волн для физиков: Учебное пособие, М.: Интеллект, 2011.

3. Котов М.А., Рулева Л.Б., Солодовников С.И., Суржиков С.Т. Исследование ударно-волновых процессов обтекания клиновидных моделей с кавернами в гиперзвуковой ударной аэродинамической трубе//Физико-химическая кинетика в газовой динамике. 2014. Т. 15, вып. 3. http://chemphys.edu.ru/issues/2014-15-3/articles/223/

4. Котов М.А., Крюков И.А., Рулева Л.Б., Солодовников С.И., Суржиков С.Т. Расчетно-экспериментальное исследование структуры гиперзвукового потока в плоском канале сложной конфигурации // Вестник МГТУ им. Н.Э. Баумана. Серия «Машиностроение». 2015. №1 (100).

5. Shang J.S., and Surzhikov S.T. Simulating Nonequlibrium Flow for Ablative Earth Reentry. Journal of Spacecraft and Rockets 47 (5), (2012).

6. Surzhikov S.T. Convective Heating of Small-Radius Spherical Blunting for Relatively Low Hypersonic Velocities. High Temperature 51 (2), (2013).

7. Surzhikov S.T. Radiative gas dynamics of the Fire-II superorbital space vehicle. Technical Physics 61 (3) (2016).

8. Shang J.S., Chang C.L., and Surzhikov S.T. Simulating hypersonic magnetofluid-dynamic compression in rectangular inlet. AIAA Journal 45 (11) (2007). 
9. Shang J.S., Surzhikov S.T. Plasma Dynamics for Aerospace Engineering. Cambridge University Press (2018).

10. Суржиков С.Т. Компьютерная аэрофизика спускаемых космических аппаратов. Двухмерные модели. М.: Физматлит (2018).

11. Bradley, I.N.: Shock Waves in Chemistry and Physics. Methuen and Co. Ltd., London; John Wiley and Sons Inc., New York (1962).

12. Downey, M.S., Cloete, T.J. \& Yates, A.D.B. A rapid opening sleeve valve for a diaphragmless shock tube. Shock Waves (2011) 21: 315.

13. Tranter, R.S., Brezinsky, K., Fulle, D.: Design of a high-pressure single pulse shock tube for chemical kinetic investigations. Rev. Sci. Instr. 72, 3046-3054 (2001).

14. Simpson, T.R., Chandler, C.J., Bridgman, K.B.: Effect on shock trajectory of the opening time of diaphragms in a shock tube. Phys. Fluids 10, 1894-1896 (1967).

15. Исаков С.Н., Исаков И.Н., Юркин С.В. Патент РФ №2066656 «Пусковая установка».

16. Isakov S.N., Yurkin S.V. Патент США № 7232152 «Method of bringing to readiness an inflatable airbag of safety device, safety device for a vehicle, valve device».

17. НосоваЕ.В., Пискунов В.А., Носов В.В. Расчет на прочность запорного колпака быстродействующего пневматического клапана // Современное машиностроение. Наука и образование. 2013. № 3 .

18. Григорьев В.В., Исаков С.Н., Петров Р.Л., Юркин С.В. Газодинамическое исследование пневматического линемета // Журнал технической физики, 2006, том 76, вып. 3.

19. Булович С.В., Виколайнен В.Э., Петров Р.Л. Численное решение задачи о формировании течения в цилиндрической трубе при открытии кольцевой щели // Письма в ЖТФ, 2007, том 33, вып. 23.

20. http://www.ista-pneumatics.ru/

21. Котов М.А. Расчетно-экспериментальные исследования ударно-волновых процессов в гиперзвуковой ударной аэродинамической трубе. Диссертация на соиск. уч. степ. к.ф.-м.н., ИПМех PAH, 2014.

22. Котов М.А., Рулева Л.Б., Солодовников С.И. Повышение точности экспериментальных работ на ГУАТ//Физико-химическая кинетика в газовой динамике. 2014. Т. 15, вып. 1. http://chemphys.edu.ru/issues/2014-15-1/articles/105/

23. Анурьев В.И. Справочник конструктора-машиностроителя. Том 1. М.: Машиностроение, 2006.

24. Долматовский Г.А. Справочник технолога по механической обработке металлов. М.: Машгиз, 1962. 